\title{
Myocardial biopsies differentiate between myocyte- and endothelial-targeted myocarditis
}

Received: 28 May 2011; Accepted: 15 April 2012; First published online: 22 May 2012

We appreciated the review of the current literature to paediatric myocarditis by Lindsay J. May et $\mathrm{al}^{1}$ (June 2011 issue). Regarding the evolving approach, we would like to underline the meaning of myocardial biopsies even in terms of the shift from coxsackievirus $\mathrm{B}$ to adenovirus and, in the past 5 years, to parvovirus B19. ${ }^{2}$ In this context, we missed the pathogenetic features of inflammatory cardiomyopathy in terms of the fundamental difference between a coxsackievirus myocarditis and parvovirus B19 vasculitis-dependent cardiomyopathy, knowing well that endothelial cells but not cardiac myocytes are the Parvo B19-specific target cells in patients with Parvo B19-associated myocarditis. ${ }^{3,4}$ Taking this novel pathogenetic knowledge into account, the injury process of inflammatory cardiomyopathy is newly lightened. The question arises as to whether any newly diagnosed myocarditisdependent cardiomyopathy really has a pathogenesis, as reviewed by the authors, or is it time to use all current diagnostic tools to differentiate between a primary cardiac myopathy in which the myocytes are the primary targets and a vascular disease with secondary ischaemic cardiac myocytes damage? Such a differentiation makes sense not only in consideration of the prognostic difference between the causal viral entities, but also with respect to the current efficacy of gamma-globulin therapy and in particular to novel therapeutic strategies such as cardiac stem cell therapy.

$$
\begin{array}{r}
\text { Dietmar Schranz } \\
\text { Department of Paediatric Cardiology } \\
\text { Justus-Liebig University } \\
\text { Giessen, Germany } \\
\text { Ina Michel-Behnke } \\
\text { Department of Paediatric Cardiology } \\
\text { Medical University of Vienna } \\
\text { Vienna, Austria }
\end{array}
$$

\section{References}

1. May LJ, Patton DJ, Fruitman DS. The evolving approach to paediatric myocarditis: a review of the current literature. Cardiol Young 2011; 21: 241-251.

2. Cooper LC. Medical progress, myocarditis. N Engl J Med 2009; 360: 1526-1538.

3. Klingel K, Sauter C, Bock CT, et al. Molecular pathology of inflammatory cardiomyopathy. Med Microbiol Immunol 2004; 193: 1001-1107.

4. Duechting A, Tschöpe C, Kaiser H, et al. Human parvovirus B19 NS1 protein modulates inflammatory signalling by activation of STAT3/PIAS3 in human endothelial cells. J Virol 2008; 82: 7942-7952.

5. Strauer BE, Brehm M, Schannwell CM. The therapeutic potential of stem cells in heart disease. Cell Prolif 2008; 41 (Suppl 1): 126-145. 